Financial support. No financial support was provided relevant to this manuscript.

Conflicts of interest. All authors report no conflicts of interest relevant to this manuscript.

\section{References}

1. Ogoina D, Izibewule JH, Ogunleye A, et al. The 2017 human monkeypox outbreak in Nigeria-report of outbreak experience and response in the Niger Delta University Teaching Hospital, Bayelsa State, Nigeria. PloS One 2019;14: e0214229.

2. Ježek Z, Szczeniowski M, Paluku K, Mutombo M. Human monkeypox: clinical features of 282 patients. J Infect Dis 1987;156:293-298.

3. Petersen BW, Kabamba J, McCollum AM, et al. Vaccinating against monkeypox in the Democratic Republic of the Congo. Antivir Res 2019;162:171-177.

4. Nakoune E, Lampaert E, Ndjapou SG, et al. A nosocomial outbreak of human monkeypox in the Central African Republic. Open Forum Infect Dis 2017;4(4):ofx168
5. Petersen E, Abubakar I, Ihekweazu C, et al. Monkeypox-enhancing public health preparedness for an emerging lethal human zoonotic epidemic threat in the wake of the smallpox post-eradication era. Int J Infect Dis 2019;78:78-84.

6. Senthilingam M. Third case of monkeypox reported in the UK, in health care worker CNN website. https://edition.cnn.com/2018/09/26/health/ third-monkeypox-case-uk-intl/index.html. Accessed November 16, 2019.

7. Guideline for isolation precautions: preventing transmission of infectious agents in healthcare settings. Centers for Disease Control and Prevention website. https://www.cdc.gov/infectioncontrol/guidelines/isolation/index. html. Published 2007. Accessed November 16, 2019.

8. Monthly international visitor arrivals. Singapore Tourism Board website. https://www.stb.gov.sg/content/stb/en/statistics-and-market-insights/tourismstatistics/international-visitorarrivals.html. Accessed November 16, 2019.

9. Monkeypox-Singapore. World Health Organization website. https://www. who.int/csr/don/16-may-2019-monkeypox-singapore/en/. Accessed November 16, 2019.

\title{
Methods of a study of terminal cleaning of patient rooms
}

\author{
John D. Coppin BS, MPH${ }^{1}$, Frank C. Villamaria BS, MPH, MS ${ }^{1}$, Marjory D. Williams PhD, RN ${ }^{1,2}$, Laurel A. Copeland PhD ${ }^{3}$, \\ John E. Zeber $\mathrm{PhD}^{1,4}$ and Chetan Jinadatha MD, MPH ${ }^{5,6}$ (D) \\ ${ }^{1}$ Department of Research, Central Texas Veterans' Healthcare System, Temple, Texas, '2Department of Nursing, Central Texas Veterans' Health Care System, \\ Temple, Texas, ${ }^{3}$ Veterans' Affairs Central Western Massachusetts Healthcare System, Leeds, Massachusetts, ${ }^{4}$ University of Massachusetts Amherst School of \\ Public Health \& Health Science, Amherst, Massachusetts, ${ }^{5}$ Department of Medicine, Central Texas Veterans' Health Care System, Temple, Texas and ${ }^{6}$ College \\ of Medicine, Texas A\&M Health Science Center, Bryan, Texas
}

To the Editor-It is encouraging to see that people have reviewed our article "Increased Time Spent on Terminal Cleaning of Patient Rooms May Not Improve Disinfection of High-Touch Surfaces." ${ }^{1}$ However, a related Letter to the Editor raises concerns that some may be misinterpreting both the thrust of our paper and our study methodology. ${ }^{2}$

In our pragmatic report, we aimed to promote better cleaning by presenting research results that suggest that more than adequate time spent on terminal cleaning may not result in additionally lower bioburden on high-touch surfaces. We hope this information will cause practitioners to focus on other important factors such as proper training for environmental services staff (EVS), proper use of appropriate chemicals, and targeting high-touch surfaces that pose the greatest risk for transmission of pathogens to patients. We reiterated that adequate cleaning time is crucial, and we certainly do not advocate taking any shortcuts in the terminal cleaning process. Yet, as in many things, it is the quality of the process not the quantity that counts.

As to methodology, EVS were well-trained and experienced, and they voluntarily collaborated on the project. They were instructed to follow the manufacturer's guidelines for application and contact time. We did not monitor EVS during room cleaning to avoid the Hawthorne effect and to obtain data on unmonitored cleaning.

The 5 high-touch surfaces chosen were the highest-touch surfaces according to published papers at the time of the study. ${ }^{3} \mathrm{We}$ omitted details on the culture process and instead referenced a prior paper. ${ }^{4}$

Author for correspondence: Chetan Jinadatha, E-mail: chetan.jinadatha@va.gov

Cite this article: Coppin JD, et al. (2020). Methods of a study of terminal cleaning of patient rooms. Infection Control \& Hospital Epidemiology, 41: 375-376, https://doi.org/ $10.1017 /$ ice.2019.361
Our analysis plan followed best practices for analyzing count data: use a generalized linear model with appropriate choice of family and link function, and avoid log transforming the data. ${ }^{5}$ We used Bayesian models and reported uncertainty in our estimates, rather than rely on a p-value. Recent articles highlight the pitfalls of statistical significance, which can be particularly problematic in small observational studies without preregistration. ${ }^{6}$ Major journals are now requiring some form of uncertainty interval rather than $P$ values. ${ }^{7}$ We also chose to include model estimates on the actual outcome scale. This makes interpretation easy for those familiar with the outcome (ABC counts from press plates) but not familiar with statistical terminology like incident rate ratios. Our goal was to apply the best methods of analysis and interpretation.

Finally, we provided a full financial support disclosure statement in our article. The salary support for this study was provided by the authors' employers.

Acknowledgments. The views expressed in this article are those of the authors and do not necessarily represent the views of the Department of Veterans' Affairs. Xenex Healthcare Service did not participate in study design or in the collection, analysis, and interpretation of data or in the writing of the report or in the decision to submit the paper for publication.

Financial support. This study was supported by a merit review grant from the Department of Veterans' Affairs to J.Z. (grant no. IIR 12-347), and laboratory activity was supported by a grant from Xenex Healthcare Services, with additional support from the Central Texas Veterans' Health Care System (Temple, TX), Scott \& White Healthcare (Temple, TX), and the jointly sponsored Center for Applied Health Research (Temple, TX).

Conflicts of interest. All authors declare no competing interests. 


\section{References}

1. Coppin JD, et al. Increased time spent on terminal cleaning of patient rooms may not improve disinfection of high-touch surfaces. Infect Control Hosp Epidemiol 2019;40:605-606.

2. Hooker EA. Increased time spent on terminal cleaning of patient rooms may not improve disinfection of high-touch surfaces. Infect Control Hosp Epidemiol 2019;40:1086.

3. Huslage K, Rutala WA, Sickbert-Bennett E, Weber DJ. A quantitative approach to defining "high-touch" surfaces in hospitals. Infect Control Hosp Epidemiol 2010;31:850-853.
4. Jinadatha C, Villamaria FC, Ganachari-Mallappa N, et al. Can pulsed xenon ultraviolet light systems disinfect aerobic bacteria in the absence of manual disinfection? Am J Infect Control 2015;43:415-417.

5. O'Hara RB, Kotze DJ. Do not log-transform count data. Methods Ecol Evol 2010;1:118-122.

6. Amrhein V, Greenland S, McShane B. Retire statistical significance. Nature 2019; 567:305-307.

7. Harrington, D. et al. New guidelines for statistical reporting in the journal. N Engl J Med 2019; 381:285-286.

\title{
Impact of peer comparison on carbapenem use among inpatient prescribers at a community hospital
}

\author{
Rossana M. Rosa MD ${ }^{1}$ and Amanda M. Bushman PharmD² \\ ${ }^{1}$ Infectious Diseases Service, UnityPoint Health-Des Moines, Des Moines, lowa and ${ }^{2}$ Department of Pharmacy, UnityPoint Health-Des Moines, Des Moines, lowa
}

To the Editor-The Infectious Diseases Society of America (IDSA) guidelines for the implementation of an antimicrobial stewardship program (ASP) recommend using preauthorization, prospective review, and feedback or a combination of these as core strategies for ASPs. ${ }^{1}$ Behavioral interventions, such as peer comparison, are included among the Core Elements of Outpatient Antimicrobial Stewardship developed by the Centers for Diseases Control and Prevention (CDC). ${ }^{2}$ However, evidence on the use of peer comparison by inpatient ASPs is limited.

To further understand the applicability of a behavioral intervention in this setting, we conducted an intervention consisting of peer comparison of the quantitative and qualitative use of carbapenems among inpatient prescribers. The main outcome of interest was carbapenem days of therapy (DOT) per 1,000 patient days. This study was conducted at a 374-bed hospital and its level 1 trauma center in Des Moines, Iowa. The preintervention period was December 1, 2016, to November 30, 2017, and the postintervention period was December 1, 2017, to November 30, 2018.

The intervention was limited to internal medicine and surgery house staff, and the hospitalists, critical care specialists, and surgeons directly working with house staff. These 5 groups of "peers" were used for direct comparisons. By targeting these groups we estimated that we would reach $>80 \%$ of the prescribers of carbapenems at our facility.

Each DOT prescribed was reviewed and its appropriateness was determined based on previously published definitions. ${ }^{3}$ Each DOT was assigned to the physician considered to be directly responsible for the patient's care that day, which was determined by authorship of progress notes. In cases in which house staff authored the progress note, both attending and trainee were assigned the DOT. The component of the peer comparison report concerning quantitative use was calculated by adding the number of DOTs

Author for correspondence: Rossana M. Rosa MD, E-mail: rossana.m.rosa@gmail. com$^{*}$ PREVIOUS PRESENTATION: The results from this study were presented at ID Week 2019, on October 4, 2019, in Washington, DC.

Cite this article: Rosa RM and Bushman AM. (2020). Impact of peer comparison on carbapenem use among inpatient prescribers at a community hospital. Infection Control \& Hospital Epidemiology, 41: 376-378, https://doi.org/10.1017/ice.2019.377 adjudicated to each physician. The component indicating appropriateness of use was calculated using the following formula:

Percentage of appropriate use by physician

= Total no. of appropriate DOT by physician/

Total no. of DOT by physician

A similar calculation was done for each peer group using the following formula:

$$
\begin{aligned}
& \text { Percentage of appropriate use by peer group } \\
& =\text { Total no. of appropriate DOT by peer group/ } \\
& \text { Total no. of DOT by peer group }
\end{aligned}
$$

Reports on quantity and appropriateness by each individual and in comparison with their peers were sent by e-mail on a monthly basis (Supplemental Material online).

An interrupted time series analysis was preferred to determine changes in the slope of rate of hospital-level carbapenem DOT per 1,000 patient days following onset of intervention. The impact of the intervention was modeled as a gradual change in the trend of carbapenem use, and a Poisson regression model was used. Data were assessed for autocorrelation and none was found. No other interventions targeting carbapenem use were implemented during this study period.

During the 12 months of the intervention, an average of 24 e-mails per month were sent and a total of 91 physicians were contacted. The average carbapenem DOT per 1,000 patient days was 15.6 in the preintervention period and 15.2 in the postintervention period.

Following onset of the intervention, no change in the trend of carbapenem use was observed (incidence rate ratio [IRR], 1.04; $95 \%$ confidence interval $[\mathrm{CI}], 0.98-1.10 ; P=.21$ ) (Fig. 1a). The impact of the intervention was also analyzed by medical and surgical services, and trends of carbapenem use also remained stable. In the medical service the IRR was 0.98 (95\% CI, 0.92-1.05; $P=.612$ ) (Fig. 1b), and in the surgical service, the IRR was 1.05 (95\% CI, 0.99-1.13; $P=.11$ ) (Fig. 1c). The percentage of 